\title{
Management of development of innovative ecosystems in reclamation
}

\author{
Irina Yurchenko ${ }^{1 *}$, Mikhail Bandurin ${ }^{2}$, and Inna Bandurina $^{2}$ \\ ${ }^{1}$ All-Russia Research Institute of Hydraulic Engineering and Reclamation by the name of AN Kostyakov, Bolshaya Akademicheskaya \\ str., 44, Moscow, 127550 Russia \\ ${ }^{2}$ Kuban State Agrarian University named after IT Trubilin, Kalinina str., 13, Krasnodar, 350044Russia
}

\begin{abstract}
In the context of the coming digital globalization of the economy, an important factor in increasing the level of development of ameliorated agriculture is the widespread introduction of innovative agricultural technologies and agricultural production management into the practice of the domestic agroindustrial complex. The methodological basis of research is based on information and analytical methods, methods of expert assessments, system analysis and synthesis. Based on the results of the studies and the performed assessment, the role of innovation systems in the structure of the agricultural production economy and the experience of their application in the ameliorative sector of the economy in comparison with developed foreign countries are characterized. The influence of innovations on the efficiency and productivity of labor is shown and proposals are presented to reduce and eliminate the technological backwardness of agricultural production on reclaimed lands, consistent with the trends in the development of technologies for the production of advanced industries of the domestic and world economy. The main stages of the formation of production management systems, which provide support for the assignment of control actions, are presented. Reasons are revealed that hinder the full use of innovative technologies in agricultural production, associated with the lack of free funds among small-scale agricultural producers and their proper understanding of the strategic importance of innovations in the production process. A prognostic analysis of the innovative development of agricultural production based on "intelligent agricultural technologies", is presented which unites objects via the Internet for receiving and exchanging information from built-in services.
\end{abstract}

\section{Introduction}

The need for a timely and effective solution to one of the most important and priority tasks of the agro-industrial complex of the Russian Federation-the achievement of the best world-class indicators by domestic agricultural production-led to the industry's interest in the development of an innovative system for precision crop production management, which is a powerful toolkit for raising the economic level of agricultural technologies [1]. In this regard, studies devoted to the precise management of reclaimed agroecosystems are very relevant and in demand.

In modern realities, examples of the successful use of precision control of technological processes on reclaimed lands in domestic agricultural production are clearly not enough. Traditionally, agricultural production has been the most conservative sector of the economy. Low profits, high levels of risks of failure to achieve the planned economic results due to the difficult to predict variability of the cost of consumed material and technical resources and commodity products, a multi-tier chain of suppliers, etc. are the factors that hinder the intensity of the inflow of private investment and require constant government support from both domestic and foreign agricultural producers [2]. In the latter case, the share of state support can exceed $30 \%$.

At the same time, it becomes clear that the economy of the domestic agro-industrial complex is now confidently striving for the achievements of successfully developing Russian production sectors [3]. For the period from 2012 to 2018, the growth of Russian agricultural production amounted to $15 \%$, which is three times higher than the growth rate of the country's gross domestic product, which reflects the market value of all domestic final goods and services, which amounted to no more than $5 \%$. But this is significantly lower than the volume of supplies of agricultural products from the world's leading exporters, which is largely due to the imperfection of crop farming agricultural technologies [4].

The existing level of use of creative resource and energy-saving operations, including in terms of the effective use of irrigation water, the use of innovative reclamation solutions, leads to the lag of Russian indicators of efficiency and labor productivity from those of world leaders. The grain yield in Russia does not exceed $29.2 \mathrm{c} / \mathrm{ha}$, which is much lower than the yield

* Corresponding author: chepura@mail.ru 
of grain crops achieved in many countries with high-tech crop production systems (in the EU countries it amounts to $40 \mathrm{c} / \mathrm{ha}, 56 \mathrm{c} / \mathrm{ha}$ in China and $60 \mathrm{c} / \mathrm{ha}$ in the USA) [5].

The national innovation system of each country, including the structure, goals, functions, is formed and transformed depending on both the level of economic development of the state, the initial state of the scientific and technological complex, personnel potential and mentality of workers, and the established strategic priorities of the state innovation policy and the tasks to be solved [6].

Forcing the technological backwardness of agricultural production on ameliorated lands is a complex multicomponent problem. Its modern solution is linked to the transition of agricultural production to technological structures of a higher level 5.6 (according to the classification of the state innovation strategy) from the actually achieved level 4. The transition of agricultural production to new innovative technological paradigms will require the implementation of new technical, technological, organizational and other solutions that characterize the distinctive features of these paradigms: biotechnology, artificial intelligence, the use of the Internet and an integrated high-speed communication system, etc. [7].

Combining operational data with intelligent digital applications that process information in real time opens up new prospects for increasing the validity of decisions on the appointment of corrective actions, implementing the control of natural factors, multivariate calculations, analysis of an expanded set of indicators, forecasting, modeling, assessing the consequences of decisions made and other methods of high-precision formation of agricultural technological processes, ensuring the feasibility of developing innovative agricultural production management systems on reclaimed lands.

\section{Materials and methods}

The purpose of this work is to consider the evolution of the formation of innovative systems for managing agricultural production on reclaimed lands in the domestic agro-industrial complex in comparison with developed countries of the West, the United States of America, Canada and other states, as well as to assess their role in the structure of the economy of agricultural production. The implementation of this goal required the solution of the following tasks:

- carrying out an analytical assessment of the formation of digitalization of production processes and production in the sphere of land reclamation of the domestic agro-industrial complex;

- determination of the structure and degree of saturation of the world market with innovative farming technologies;

- consideration of conceptual approaches to the development trends of precision management systems for the reclamation regime of the agroecosystem in the era of global digitalization of the country's economy.

The novelty of the research lies in the development of a scientific substantiation of the need and feasibility of digitalization of the management system of the reclamation water complex based on technologies for solving the fundamental problems of agricultural production formed by the information computer digital platform of the melioration sphere. The practical significance is in determining the fundamental provisions for the development of a functional structure and organizational measures for the introduction of powerful tools for full-factor automation of procedures for managing the reclamation regime of agroecosystems.

The methodological basis of the performed research work was formed by the information and analytical method, expert assessments, system analysis and synthesis [8].

\section{Results and discussion}

The Western European, or Euro-Atlantic, model of the national innovation system, widespread in many Western European countries, with their well-known world-class scientific centers dating back many years, corresponds to the strategy of increasing innovation. The model contains all phases of the innovation life cycle, covering fundamental and applied science, high-quality education, the creation of innovations and their mass commercialization [9].

A certain recession in the European economy, which occurred after the devastating Second World War, made most countries to abandon expensive scientific research requiring mega-installations (the so-called "big science") even where such work had previously been carried out. European researchers focused mainly on relatively inexpensive, but priority research in biology, chemistry, pharmacology, and other areas that are effective in practical implementation and commercialization.

At that time, in foreign practice, much attention was paid to improving the systems of assistance in making managerial decisions, the basis of which was the automation of operations and procedures for assigning control actions [10]. The beginning of this process was laid by the formation of computer management information systems (MIS), which guaranteed the development of the requested reports, generated according to the preferences of the decision maker. Beginning in the sixties of the last century, the formation of model-oriented digital systems of assistance in the appointment of control actions has been noted.

In 1970-1980, commercial digital technologies were practiced [11] intended for:

- the formation of a proper system of data for the management of economic entities in the procedures for assigning control actions (Executive Information System, EIS);

- the provision of collective solutions to a single problem (group decision support system, GDDS);

- the solution of integral interdepartmental problems that required theoretical training from the manager and the practice of its implementation in various production sectors of the enterprise (organizational decision support system, ODDS). 
The nineties of the 20th century were marked by the development of specialized DSS with the functionality of online analysis and data transformation in the Online mode for the implementation of fundamental key decisions (Online analytical processing, OLAP). Analysis of the observed trends in the field of improving management and assessing the priorities of the evolution of digital technologies in the field of agricultural reclamation revealed the advantages of DSS as the most appropriate system meeting the requirements of operational and strategic management of information and economic processes in the specified sector of the economy [12].

The integration of DSS-based software into the monitoring of the state of agroecosystems contributes to the formation and evolution of a priority approach to innovations in agricultural production-technologies of precision (highly accurate) farming. The implementation of these new studies and the emergence of fruitful results in the field of control theory in general and in the field of optimization of production process control, in particular, is associated with the powerful development of electronic and computer technologies and was initiated by the urgent need of oil, gas and food production, water supply, energy supply and other sectors of the economy in the evolution of management of a spatially distributed infrastructure of remote objects. The results obtained were initially used in crop production by successful municipalities to automate irrigation of lawns, golf courses, etc., and subsequently to create an automated process control system for irrigation systems in agricultural production.

The indicators of the Euro-Atlantic countries leading in terms of economic development demonstrate an enviable stability. Their place in the ratings changes only slightly and they, invariably, confirm their status as world leaders. Currently, in the countries of Western Europe, there are two quite distinct trends in the formation of innovative technologies: on the one hand, self-reliance, and the integration of the scientific and innovative potential of individual countries into a single European research space, on the other. Applied research is supported by both state grants and projects carried out at the expense of funds and in the interests of large corporations. The contribution of regional authorities, in which interests innovative projects are being developed, is also significant.

An analysis by the University of Nebraska-Lincoln established the ongoing interest of farmers in precision farming technologies. The work analyzed the results of a questionnaire survey of 126 participants of the Nebraska Extension exhibitions in 2015 [13].

The report notes:

- the highest level of application of digital technologies for collecting and analyzing soil samples (98\%) and high-speed Internet (94\%);

- active usage of productivity control and accounting systems, farmland mapping, GPS navigation technologies (more than $80 \%$ );

- the demand for systems for the differentiated application of fertilizers $(68 \%)$;
- the growing popularity of satellite and aerial photographs, the use of which is approaching $30 \%$.

It should be recognized that there is a fairly high degree of implementation of innovative farming technologies in the world market, primarily in the American and European markets. In Europe, the priority of introducing new technologies into agricultural production belongs to Germany. China and India have achieved good results in mechanization and automation of crop production. By 2050, it is planned to increase the specified target world market to $\$ 240,000$ million, which indicates the impact of innovative digital technologies on the development of agribusiness [14].

The factors that caused such global changes in the organization of agricultural production include:

- a decrease in the growth rate of the world agricultural market to $3 \%$ per year, which negatively affects the provision of food to the growing population of the planet [15];

- shortage and complete depletion of resources after extensive development of agricultural production, primarily land and water [16];

- development and availability of systems for collecting, analyzing and processing data that provide control, study and assessment of the current state of agroecosystems and forecast the consequences of management decisions, which has a positive effect on saving finances, labor costs and time [17].

The currently observed next stage of innovative development of agricultural production is caused by the processes of digitalization of the economy, marking the end of the "analog" period of agricultural production and the formation of the era of digitalization and mass automation of business processes, due to the state scientific and technical policy.

Following the example of the technology achievements of the Industry 4.0 project, we can talk about the Agrocomplex 4.0 technology revolution, which promises to ensure the productivity of farmland that exceeds the maximum results from the introduction of mechanization, the use of herbicides and the use of genetically modified seeds. The basis of the functional structure of this complex is "intelligent (smart) agricultural technologies" integrated as part of AIoT projects (Agricultural Internet of Things), which unite objects via the Internet to receive and exchange information from built-in services [18].

The goal of the AIoT project is to automate the entire set of agro-technological operations for the cultivation of agrocenoses. The constant components of the project include AIoT platforms [19], which unite a group of technologies that are used as a basis for creating a specific and specialized system of digital interaction for the development of industry web applications [20]. The platform software complex ensures the operation of remote devices for receiving data and assigning control actions, regulates the receipt and storage of data, as well as their information security.

There are clearly not enough examples of effective use of the full-fledged capabilities of intelligent precision technologies in domestic agricultural production. Only sufficiently large enterprises can carry 
out a full-fledged re-equipment of production. Smallscale producers, which make up the bulk of economic entities in agricultural production, lack both free funds and strategic thinking due to their local integration into a single global production process of the agro-industrial complex [21].

According to the estimates of the Grand View Research group, in 2017 the value of the intelligent agricultural production market in the Russian Federation was $\$ 221,800 \mathrm{~K}$, which slightly exceeded $1.2 \%$ of the value of a similar market in the world. Among the domestic organizations involved in the implementation of specialized software on the IoT platform, Rightech and JSC "Component" stand out which effectively transform the indicators received from different sensors [22]. Rigtech and kSense IoT platforms automate the monitoring of road transport and agricultural machinery, storage and processing of agricultural products, monitoring the state of agrocenoses and managing livestock.

The developments of ExactFarming company are focused on managing the productivity of phytocenoses and the profitability of agricultural production using the ExactFarming online service/mobile application. The Smart4agro program complex from Alan IT implements a choice of control actions in the field of agricultural production, monitoring the state of farmland based on a cloud service with geoinformation and analytical support. IoT design in the Russian Federation is also carried out by Strizh Telematics and LEIS LLC.

The world leader in the development of digital technologies for transport and agricultural production is held by Iteris Inc (USA), which provides consulting support on weather forecasting, the use of irrigation water, the state of soil fertility and phytocenosis, implementing software and hardware tools for the precision management platform of agricultural production of its own original design and mobile application ClearAg.

Leading participants in the smart farming market abroad are also companies of the United States (John Deere, Trimble, Raven Industries, AGCO Corporation, Ag Leader, Autonomous Solutions), the Netherlands (CNH Industria), Germany (CLAAS) and Canada (Farmers Edge).

\section{Conclusion}

Thus, the transition to intelligent agricultural production is becoming inevitable, although it is proceeding more slowly than it should be. This makes it obvious the need for the timely development of the concept of a digital platform for a reclamation water management complex, providing services for solving the main production problems in the field of agricultural reclamation.

\section{References}

1. N. Yusupbekov, F. Adilov, F. Ergashev Journal of Automation, Mobile Robotics \& Intelligent Systems 11(3) 53-57 (2017)
2. E. V. Kuznetsov, A. E. Khadzhidi, Y. A. Poltorak, M. Kuznetsova EurAsian J. of BioSciences 13(1) 315-321 (2019)

3. J. Carr Publishing house Secret of the firm (2005)

4. D. V. Kozlov Water Resources, 28(2) 215-219 (2001)

5. M. A. Bandurin, I. F. Yurchenko, I. P. Bandurina International Multi-Conference on Industrial Engineering and Modern Technologies, FarEastCon 2019, 8933970 (2019)

6. I. V. Bogachev Forum Cnews Transcript of the speech on November 14, 2013 Moscow (2013)

7. V. I. Olgarenko, G. V. Olgarenko, I. V. Olgarenko Melioration and water management 6 8-11 (2013)

8. T. Safronova, S. Vladimirov, I. Prikhodko, A. Sergeyev E3S Web of Conferences 21005014 (2020)

9. D. A. Markov Izvestiya of the Russian State Pedagogical University. A. I. Herzen 12(90) (2009)

10. F. K. Abdrazakov, S. S. Orlova, T. A. Pankova, E. N. Mirkina, O. V. Mikheeva Journal of Interdisciplinary Research 8(1) 154-161 (2018)

11. L. V. Kireicheva, N.P. Karpenko Eurasian soil science 48(5) 524-532 (2015)

12. Report "Digital Russia: New Reality" (2017)

13. M. Porter Competition M: Ed. House "Williams" (2003)

14. S. Vladimirov, I. Prikhodko, T. Safronova, E. Chebanova E3S Web of Conferences 17512010 (2020)

15. V. I. Olgarenko, I. V. Olgarenko, V. I. Olgarenko IOP Conference Series: Materials Science and Engineering, 698(2) (2019)

16. L. V. Kireicheva, O. A. Zakharova Eurasian Soil Science, 35(9) 990-995 (2002)

17. B. P. Chesnokov, O. V. Naumova, V. A. Strelnikov, F. K. Abdrazakov, B. A. Tronin International Journal of Applied Engineering Research, 11 2140-2144 (2016)

18. M. A. Bandurin, V. A. Volosukhin, A. V. Mikheev, Y. V. Volosukhin, I. P. Bandurina, IOP Conference Series: Materials Science and Engineering, 327(2), 022010 (2018)

19. T. Jaegers Eurostat Statistics in focus (2013)

20. Vater Hendrick, Bail Elena. Haufe-Lexware $m b H \& C o$ (2013)

21. P. Watson, N. Chileshe, D. Maslow A Construction Industry Development 2nd Postgraduate Conference -Cape Town South Africa 129-141 (2004)

22. M. A. Bandurin, V. A. Volosukhin, A. V. Mikheev, Y. V. Volosukhin, I. P. Bandurina International conference on mechanical engineering, automation and control systems 327 (2017) 